\title{
MARKERS OF INFLAMMATION IN PATIENTS WITH PSORIASIS VULGARIS AND PSORIATIC ARTHRITIS
}

\author{
Stoyan Pavlov ${ }^{1}$ Irina Ivanova ${ }^{2}$, Daniela Gerova ${ }^{3}$ \\ ${ }^{1}$ Clinic of Dermatology and Venereology, Faculty of Medicine, Medical University of Varna \\ ${ }^{2}$ Department of Gastroenterology, Faculty of Medicine, Medical University of Varna \\ ${ }^{3}$ Clinical Laboratory, UMHAT St. Marina
}

\begin{abstract}
INTRODUCTION: The pathogenesis of psoriasis is complex. Genetic factors have a basic role, followed by immunological disturbances, which have been found to provoke a chronic inflammatory process affecting the skin and joints. The study aimed to establish and analyze the relationship between the inflammatory manifestations and vitamin $D$ status in the patients with psoriasis.

MATERIALS AND METHODS: We examined 113 patients with moderate or severe psoriasis, divided into two groups for analysis: presence of psoriasis without psoriatic arthritis $(n=73)$ and with psoriatic arthritis $(\mathrm{n}=40)$. Clinical data for inflammation were assessed by Psoriasis Area and Severity Index (PASI). At hospital admission samples were collected for C-reactive protein (CRP) and blood count, as well as for 25-hydroxyvitamin D, 25(OH)D. The serum levels of 25(OH)D were tested with immune fluorescent method in 92 patients.

RESULTS: The patients with psoriatic arthritis compared to psoriatic patients without arthritis had higher C-reactive protein $(31.77 \pm 30.61 \mathrm{mg} / \mathrm{l}$ vs. $4.13 \pm 4.19 \mathrm{mg} / \mathrm{l}, \mathrm{p}<0.0001)$ and PASI $(35.20 \pm 11.31 \mathrm{vs.} \mathrm{28.82} \pm 12.51$, $\mathrm{p}=0.012)$ but lower $25(\mathrm{OH}) \mathrm{D}(10.66 \pm 8.73 \mathrm{ng} / \mathrm{ml} \mathrm{vs} .12 .98 \pm 6.23 \mathrm{ng} / \mathrm{ml}, \mathrm{p}=0.004)$. A significant correlation was found between the level of CRP and 25(OH)D, $r=-0.2631(\mathrm{p}=0.012)$ and CRP and PASI, $r=0.1993$ $(\mathrm{p}=\mathbf{0 . 0 3 6})$.

CONCLUSION: The serum level of CRP and 25(OH)D, and the vitamin D deficiency, respectively, could be accepted as markers for worse health condition according to the clinical manifestations of psoriasis, as well as the comorbid diseases.
\end{abstract}

Keywords: psoriasis; psoriatic arthritis; inflammatory markers; vitamin D deficiency

\section{INTRODUCTION}

Psoriasis vulgaris is a common chronic, systemic inflammatory disease with a typical involvement of skin and joints. Current studies discuss the

\footnotetext{
Address for correspondence:

Stoyan Pavlov, MD

Clinic of Dermatology and Venereology

Medical University of Varna,

55 Marin Drinov Str., Varna, Bulgaria

e-mail: stoyanpavlov@abv.bg
}

Received: July 16, 2016

Accepted: September 7, 2016 complex role of vitamin $\mathrm{D}$ in the pathogenesis of psoriasis. They suggest the involvement of vitamin $\mathrm{D}$ in the immune modulation, regulation of keratinocyte turnover, and the integrity of the cutaneous barrier $(1,2)$. The supporting argument is the identification of vitamin D receptors in macrophages, neutrophils, dendritic cells and T-lymphocytes (3). Accordingly, vitamin $\mathrm{D}$ status may be one of the key parameters of the functional assessment of the immune system, considering cytokine's and chemokine's homeostasis $(4,5)$. The serum concentration of 25-hydroxyvitamin $\mathrm{D}, 25(\mathrm{OH}) \mathrm{D}$, is an important accepted marker in practice, depicting the sum of skin-synthesized 
and food-derived (alimentary) vitamin D (6). In the light of current epidemiological studies, a serum level of $25(\mathrm{OH}) \mathrm{D}$ above $30 \mathrm{ng} / \mathrm{ml}(75 \mathrm{nmol} / \mathrm{l})$ is necessary for prevention of the bone pathology and for the optimal action of the other organs and systems (7).

C-reactive protein (CRP) is an established marker of inflammation. It is produced by the liver and is known as an acute-phase reagent (8). The level of CRP is used to assess the inflammatory processes in the patients with psoriasis as well as the comorbid diseases with common pathogenic mechanisms (911). Both the skin and joint involvement in psoriasis share the same inflammatory pathogenesis $(12,13)$. Elevation of CRP was found predominantly in moderate and severe psoriasis but not in mild forms of the disease (14).

Interestingly, the psoriatic patients with vitamin D insufficiency have higher CRP, sedimentation rate and risk of osteoporosis (15). The presence of arthritis in men with psoriasis is significantly associated with hypovitaminosis D (16). A recent trial evaluating the serum vitamin $\mathrm{D}$ level in 120 patients with arthritis established insufficiency and deficiency of vitamin $\mathrm{D}$ in $74 \%$ and $13 \%$ of the cases with psoriatic arthritis, $94 \%$ and $39 \%$ of the cases with rheumatoid arthritis and $97 \%$ and $38 \%$ of the cases with osteoarthritis, respectively. According to these findings the authors recommend vitamin D supplementation in all patients with arthritis (17).

Our study aimed to analyze the relationship between the vitamin D status of patients with psoriasis and clinical and laboratory markers for inflammatory manifestations of the disease.

\section{MATERIALS AND METHODS}

The study included 113 adult patients with clinical manifestations and histological confirmation of psoriasis vulgaris evaluated in the Clinic of Dermatology and Venereology at the St.Marina University Hospital for a 3-year period. The patients had moderate and severe forms of the disease (PASI $>10$ ). The cases treated with systemic therapy with biological agents or on a standard treatment with Acitretine, Cyclosporin, Methotrexate, PUVA or phototherapy were excluded from analysis. Other exclusion criteria were vitamin D supplementation, presence of neoplasm or concomitant acute or chronic infectious diseases as erysipelas, sinusitis, pyoderma, enterocolitis, hepatitis, etc.

The following data were collected: age at diagnosis and at admission; gender; body mass index (BMI) and waist circumference; C-reactive protein (CRP) and erythrocyte sedimentation rate (ESR), leukocyte and platelet count, serum level of glucose, lipids, uric acid, and creatinine. Serum levels of $25(\mathrm{OH}) \mathrm{D}$ were calculated in 92 patients by immune fluorescent test (ADVIA Centaur Vitamin D Total, Siemens) with assay range of 3.7 to $150 \mathrm{ng} / \mathrm{ml}$. Vitamin D status was classified using $25(\mathrm{OH}) \mathrm{D}$ concentration in four conditions: deficiency $(25(\mathrm{OH}) \mathrm{D}<10$ $\mathrm{ng} / \mathrm{ml})$, insufficiency $(10-30 \mathrm{ng} / \mathrm{ml})$, sufficiency $(>30$ $\mathrm{ng} / \mathrm{ml}$ ), and toxicity (>100 ng/ml). Serum 25(OH)D levels can be reported in $\mathrm{ng} / \mathrm{ml}$ (common units) or $\mathrm{nmol} / \mathrm{l}$ (SI units) with conversion formula $1 \mathrm{ng} / \mathrm{ml}$ $=2.5 \mathrm{nmol} / \mathrm{l}(18,19)$.

The disease exacerbation was assessed by the Psoriasis Area and Severity Index (PASI). The index combines the area of the affected skin (head - 10\%; upper extremities - 20\%; lower extremities $40 \%$; trunk $-30 \%$ of the whole body surface) and the grade of erythema, desquamation and infiltration or induration (scored for each criteria from 0 to 4). Regarding PASI, the psoriasis was categorized as mild (index $\leq 10)$, moderate $(>10, \leq 30)$, and severe (30 to 72 ), respectively (20).

Psoriatic arthritis was established by the presence of 3 or more criteria, according to accepted CASPAR (Classification Criteria for Psoriatic Arthritis) by National Psoriatic Foundation (21). The included 113 patients were divided into two groups for analysis: presence of psoriasis without psoriatic arthritis (group 1, $\mathrm{n}=73$ ) and psoriatic arthritis (group $2, \mathrm{n}=40)$.

The continuous variables were expressed as mean value with standard deviation. The differences between variables were analyzed with the MannWhitney test and Kruskal-Wallis test (in an analysis of more than 2 independent variables). The relationships between $25(\mathrm{OH}) \mathrm{D}, \mathrm{CRP}$ and other markers with disease characteristics were assessed using the Spearman correlation coefficients. The Fisher's exact test was used to analyze the contingency tables with categorical values. The statistics was performed with GraphPad Prism software, a trial 5.0 version. 


\section{RESULTS}

The included 113 cases were 66 male and $47 \mathrm{fe}$ male patients, with a mean age of 55.14 years (range of 19 to 81 years). $35 \%$ of the cohort of 113 patients had psoriatic arthritis. The mean age of the group 2 patients of $56.85 \pm 11.98$ years was not different to the age of all studied patients as well as the patients in group 1. The distribution of type of psoriasis is also equal in both patient's groups: type 1 psoriasis was observed in $57.53 \%$ and type 2 - in $42.47 \%$ of patients with psoriatic arthritis. The severity of disease, assessed by PASI was not different in psoriatic patients with type 1 , compared to type 2 of psoriasis. We found $47.83 \%$ prevalence of $25(\mathrm{OH}) \mathrm{D}$ deficiency and a very high rate of insufficiency - $96.74 \%$. It was interesting to find, that $25(\mathrm{OH}) \mathrm{D}$ was lower in group 2 patients - mean $10.66 \mathrm{ng} / \mathrm{ml}$, median $7.91 \mathrm{ng} / \mathrm{ml}$ (95\% CI 7.61-13.71 ng/ml), compared to group 1 - mean $12.98 \mathrm{ng} / \mathrm{ml}$, median $12.16 \mathrm{ng} / \mathrm{ml}$ (95\% CI 11.34-14.62 ng/ml), p=0.004, Figure 1. Also, the patients with psoriatic arthritis have a significantly higher level of serum CRP $(31.77 \pm 30.61 \mathrm{mg} / \mathrm{l})$, compared to the group 1 patients without arthritis $(4.13 \pm 4.19 \mathrm{mg} / \mathrm{l}), \mathrm{p}<0001$, as shown in Figure 2. In addition, the patients with psoriatic arthritis suffered from a more severe psoriatic disease than the patients in group 1: PASI $35.20 \pm 11.31$ vs. $28.82 \pm 12.51$, respectively $(\mathrm{p}=0.012)$, Figure 3 .

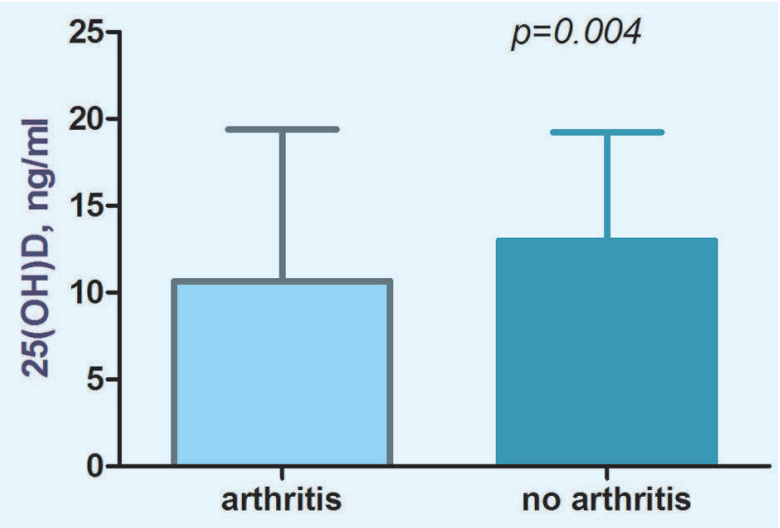

Figure 1. Serum level of 25-hydroxyvitamin D in the patients with psoriasis with and without psoriatic arthritis

A mild but significant correlation between CRP level and PASI was observed (Spearman $r=0.1993$, $\mathrm{p}=0.036$ ). The serum CRP concentration was inversely related to the calculated $25(\mathrm{OH}) \mathrm{D}(\mathrm{r}=-0.2631)$,

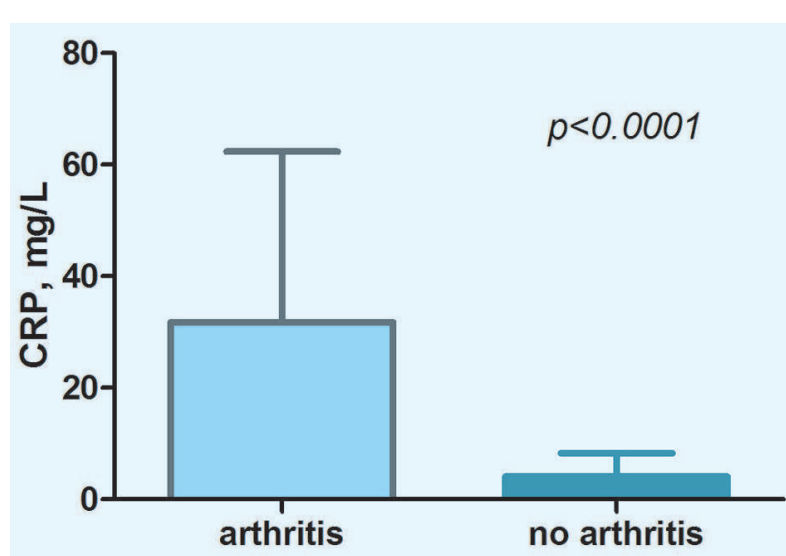

Figure 2. Level of serum C-reactive protein in the patients with psoriasis with and without psoriatic arthritis

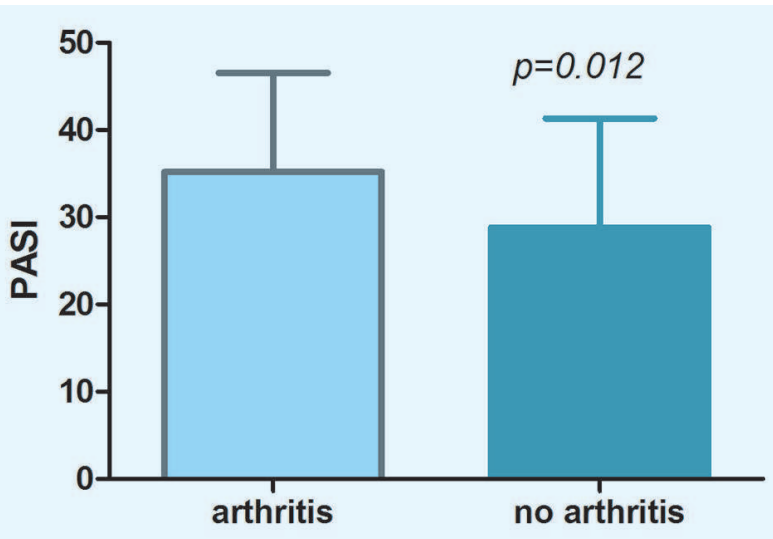

Figure 3. Severity of psoriasis, assessed by PASI in the patients with psoriasis with and without psoriatic arthritis

$\mathrm{p}=0.012$. The proportion of patients with $25(\mathrm{OH}) \mathrm{D}$ deficiency with elevated CRP was increased compared to the psoriatic patients with $25(\mathrm{OH}) \mathrm{D}$ level above $10 \mathrm{ng} / \mathrm{ml}$ : $67.4 \%$ vs. $46.8 \%$. However, the difference was not significant $(\mathrm{p}=0.057)$.

\section{DISCUSSION}

The reported incidence of psoriatic arthritis is 3.4 to 8 per 100000 in the whole population and the frequency of joint involvement in psoriatic patients has varied from 6 to $42 \%(22,23)$. In our cohort we found it to be $35 \%$. The variations are probably due to difficulties in the diagnosis of psoriatic arthritis, the need for a clinical experience of dermatologists and a cooperation with rheumatologists but also for available laboratory and image diagnostic tests. The acceptance of common diagnostic criteria - CASPAR certainly contributes to the accuracy of epidemiological and clinical trials $(21,24)$. In a study of 
174 psoriatic patients with comorbidities Gospodinov et al. observed a 53\% frequency of psoriatic arthritis. Accordingly, psoriatic arthritis was assessed as the second most common comorbidity in patients with psoriasis, after arterial hypertension, found in 96 of 174 patients (55.17\%) (25). The high prevalence of psoriatic arthritis of $35 \%$ in our study may be explained by the characteristics of psoriatic patients, having PASI $>10$ and it was previously stated that severe forms of psoriasis with large plaques and nail involvement in psoriasis have been associated with psoriatic arthritis (26).

The role of the measurement of serum CRP for assessment of severity and progression of disease was broadly studied in psoriatic cohorts of patients (14). In general, psoriatic patients had higher CRP, compared to the control groups; CRP concentrations were in association with the severity of psoriasis and a systemic therapy may achieve a decrease and normalization of the CRP (27). This relationship was observed in the subgroups of psoriatic patients with moderate and severe disease but not consistently in the patients with mild psoriasis. Therefore, in psoriasis without arthritis the CRP measurement may have an additive role or even replace PASI for assessment of disease exacerbation (14).

In our study, the group 2 psoriasis with arthritis patients had a CRP of $31.77 \pm 30.61 \mathrm{mg} / \mathrm{l}$ that was significantly increased compared to group 1 patients without arthritis. The elevation of CRP in psoriatic patients with comorbidities, incorporated to metabolic syndrome was previously established (28). Thus, the CRP level is a recommended part of the investigations in psoriasis as an appropriate marker for cardiovascular risk and psoriasis severity.

The growing number of studies evaluated the connection of vitamin D and immune inflammation. Recent study established lower vitamin D in 43 patients with plaque psoriasis, compared to 55 patients with rheumatoid arthritis, but an association with the CRP levels and PASI was not found (29). In contrast, a negative correlation between vitamin $\mathrm{D}$ and the CRP, PASI and Ischemia-modified albumin (as a marker for oxidative stress) was discovered in 43 patients with psoriasis (30). According to our data based on 92 psoriatic patients, an association of lev- els of CRP and overall decreased 25(OH)D could be established.

\section{CONCLUSIONS}

The clinical course of inflammation in patients with moderate and severe psoriasis and psoriasis with psoriatic arthritis could be assessed by simple, known markers as CRP and PASI. The serum level of $25(\mathrm{OH}) \mathrm{D}$ and vitamin D deficiency, respectively, may be accepted as a marker for a deteriorated health condition according to the clinical manifestations of psoriasis, as well as the comorbid diseases. Further prospective studies designed to estimate the association between vitamin $\mathrm{D}$, psoriasis, biochemical markers of metabolic syndrome and immunological abnormalities are needed.

\section{REFERENCES}

1. Mattozzi C, Paolino G, Richetta AG, et al. Psoriasis, vitamin $\mathrm{D}$ and the importance of the cutaneous barrier's integrity: An update. J. Dermatol. 2016;43:507-514.

2. Piotrowska A, Wierzbicka J, Żmijewski MA. Vitamin D in the skin physiology and pathology. Acta Biochim. Pol. 2016;63:17-29.

3. White JH. Vitamin D signaling, infectious diseases, and regulation of innate immunity. Infect. Immun. 2008;76:3837-3843.

4. Cantorna MT, Mahon BD. Mounting evidence for vitamin $\mathrm{D}$ as an environmental factor affecting autoimmune disease prevalence. Exp. Biol. Med. 2004;229:1136-1142.

5. Etten E van, Mathieu C. Immunoregulation by 1,25-dihydroxyvitamin D3: basic concepts. J. Steroid Biochem. Mol. Biol. 2005;97:93-101.

6. Holick MF. Vitamin D deficiency. N. Engl. J. Med. 2007;357:266-81.

7. Holick MF. Vitamin D: extraskeletal health. Rheum. Dis. Clin. North Am. 2012;38:141-60.

8. Dowlatshahi EA, Voort EAM van der, Arends LR, et al. Markers of systemic inflammation in psoriasis: a systematic review and meta-analysis. Br. J. Dermatol. 2013;169:266-82.

9. Boehncke W-H, Boehncke S. Cardiovascular mortality in psoriasis and psoriatic arthritis: epidemiology, pathomechanisms, therapeutic implications, and perspectives. Curr. Rheumatol. Rep. 2012;14:343-8. 
10. Danesh J, Wheeler JG, Hirschfield GM, et al. C-reactive protein and other circulating markers of inflammation in the prediction of coronary heart disease. N. Engl. J. Med. 2004;350:1387-97.

11. Kaptoge S, Angelantonio E Di, Lowe G, et al. C-reactive protein concentration and risk of coronary heart disease, stroke, and mortality: an individual participant meta-analysis. Lancet (London, England) 2010;375:132-40.

12. Karczewski J, Dobrowolska A, RychlewskaHańczewska A, et al. New insights into the role of $\mathrm{T}$ cells in pathogenesis of psoriasis and psoriatic arthritis. Autoimmunity 2016:1-16.

13. Adamopoulos IE, Suzuki E, Chao C-C, et al. IL17A gene transfer induces bone loss and epidermal hyperplasia associated with psoriatic arthritis. Ann. Rheum. Dis. 2015;74: 1284-92.

14. Beygi S, Lajevardi V, Abedini R. C-reactive protein in psoriasis: a review of the literature. J. Eur. Acad. Dermatol. Venereol. 2014;28:700-11.

15. Solak B, Dikicier BS, Celik HD, et al. Bone Mineral Density, 25-OH Vitamin D and Inflammation in Patients with Psoriasis. Photodermatol. Photoimmunol. Photomed. 2016;32:153-60.

16. Petho Z, Kulcsar-Jakab E, Kalina E, et al. Vitamin $D$ status in men with psoriatic arthritis: a case-control study. Osteoporos. Int. 2015;26:1965-70.

17. Grazio S, Naglic DB, Anic B, et al. Vitamin D serum level, disease activity and functional ability in different rheumatic patients. Am. J. Med. Sci. 2015;349:46-49.

18. Krasowski MD. Pathology consultation on vitamin D testing. Am. J. Clin. Pathol. 2011;136:507-14.

19. Nair R, Maseeh A. Vitamin D: The "sunshine" vitamin. J. Pharmacol. Pharmacother. 2012;3:118-126.

20. Mattei PL, Corey KC, Kimball AB. Psoriasis Area Severity Index (PASI) and the Dermatology Life Quality Index (DLQI): the correlation between disease severity and psychological burden in patients treated with biological therapies. J. Eur. Acad. Dermatol. Venereol. 2014;28:333-7.

21. Coates LC, Conaghan PG, Emery P, et al. Sensitivity and specificity of the classification of psoriatic arthritis criteria in early psoriatic arthritis. Arthritis Rheum. 2012;64:3150-5.

22. Gladman DD, Antoni C, Mease P, et al. Psoriatic arthritis: epidemiology, clinical features, course, and outcome. Ann. Rheum. Dis. 2005;64 Suppl 2:14-7.

23. Zachariae H. Prevalence of joint disease in patients with psoriasis: implications for therapy. Am. J. Clin. Dermatol. 2003;4:441-7.

24. Marchesoni A, Cantini F. Classification and clinical assessment. Reumatismo 2012;64:79-87.

25. Господинов Д. Псориатична болест - клиникоепидемиологичен анализ, коморбидност и качество на живот. Автореферат, Медицински Университет-Плевен, 2012.

26. Spelman L, Su JC, Fernandez-Peñas P, et al. Frequency of undiagnosed psoriatic arthritis among psoriasis patients in Australian dermatology practice. J. Eur. Acad. Dermatol. Venereol. 2015;29:2184-91.

27. Strober B, Teller C, Yamauchi P, et al. Effects of etanercept on C-reactive protein levels in psoriasis and psoriatic arthritis. Br. J. Dermatol. 2008;159:322-30.

28. Vadakayil AR, Dandekeri S, Kambil SM, et al. Role of C-reactive protein as a marker of disease severity and cardiovascular risk in patients with psoriasis. Indian Dermatol. Online J. 2015;6:322-5.

29. Atwa MA, Balata MG, Hussein AM, et al. Serum 25-hydroxyvitamin D concentration in patients with psoriasis and rheumatoid arthritis and its association with disease activity and serum tumor necrosis factor-alpha. Saudi Med. J. 2013;34:806-13.

30. Chandrashekar L, Kumarit GRK, Rajappa M, et al. 25-hydroxy vitamin D and ischaemia-modified albumin levels in psoriasis and their association with disease severity. Br. J. Biomed. Sci. 2015;72:56-60. 